\title{
2s-photoionisation of atomic magnesium: Shake processes and Coster-Kronig radiationless decay
}

\author{
A. G. Kochur ${ }^{1}$, D. Petrini ${ }^{2}$, and E. P. da Silva $^{3}$ \\ 1 Rostov State University of Transport Communication, 344038 Rostov-on-Don, Russia \\ e-mail: agk@jeo.ru \\ 2 Observatoire de la Côte d'Azur, Department G. D. Cassini, BP 4229, 06304 Nice Cedex 4, France \\ e-mail: petrini@obs-nice.fr \\ 3 Departamento de Física, U.F.C., CP 6030, Fortaleza 60455-760, Ceará, Brazil \\ e-mail: euclimar@fisica.ufc.br
}

Received 13 June 2000 / Accepted 20 September 2000

\begin{abstract}
. 2s-photoionization of magnesium is analyzed for incident energies ranging up to three times the $2 \mathrm{~s}$ threshold $(96.6 \mathrm{eV})$. The $3 \mathrm{~s}$ shake processes amount to almost $30 \%$ of single photoionization. The shake-up cross section $3 \mathrm{~s} \rightarrow 4 \mathrm{~s}$ exceeds $14 \%$ of the single one, and the conjugate shake-up probability plays an important role in the energy range up to three times the $2 \mathrm{~s}$ threshold. The $2 \mathrm{~s} 2 \mathrm{p}^{6} 3 \mathrm{~s}^{2}$ Auger and Coster-Kronig rates are calculated, and the $2 \mathrm{~s}^{2} 2 \mathrm{p}^{5} 3 \mathrm{~s}^{1} \mathrm{P}^{\circ}$ exit is found to be favoured (80\% of the total decay), giving rise to the line MgIII $231.73 \AA$.
\end{abstract}

Key words. atomic data - atomic processes - line formation

The aim of this research note is to examine the possibility of the production of multiply-ionized third-row elements in excited states by the double step process consisting of L-shell photoionisation followed by radiationless Auger and Coster-Kronig decays. In this way, groups of lines are emitted with relative intensities defined by the Auger parameters and radiative cascades. For third-row elements, the energies needed for ionizing $2 \mathrm{~s}$ and $2 \mathrm{p}$ subshells are relatively low compared to the energies needed for $\mathrm{K}$ ionisation of the second-row elements. We first consider the behaviour of magnesium and then comment on the more interesting cases of aluminium, silicium and phosphorus.

It is known that the creation of a $\mathrm{K}$-vacancy in thirdrow atoms starts de-excitation cascades, producing multiply charged ions via consecutive radiationless transitions (Carlson \& Krause 1965). Yields of cascade-produced ions are independent of external conditions, for example electron density and temperature, since they are due entirely to intra-atomic processes. For second-row atoms, $\mathrm{K}$-ionization can be followed by only one KLL Auger decay, therefore most of the states produced are twice ionized. The photon energies needed to photoionize the second-row atoms range from $123(\mathrm{Be})$ to $874 \mathrm{eV}(\mathrm{Ne})$. For third-row atoms the $2 \mathrm{~s}$ or $2 \mathrm{p}$ subshell can be ionized at relatively lower energies ( $\mathrm{Mg} 2 \mathrm{~s}$-subshell ionization potential is $96.5 \mathrm{eV}$, Breuckmann 1977). However, twice ionized

Send offprint requests to: D. Petrini states can still be produced via $\mathrm{L}_{1} \mathrm{~L}_{23} \mathrm{M}_{1}$ Coster-Kronig and $\mathrm{L}_{1} \mathrm{M}_{1} \mathrm{M}_{1}$ Auger transitions.

In addition to radiationless decay of the $2 \mathrm{~s}$-subshell vacancy, we also consider other mechanisms leading to multiple ionization, namely shake and conjugate shake processes. Note that if we define in a simple one configuration model the magnesium target as $2 \mathrm{~s}^{2} 2 \mathrm{p}^{6} 3 \mathrm{~s}^{2}$, the single photoionization refers to the production of $2 \mathrm{~s} 2 \mathrm{p}^{6} 3 \mathrm{~s}^{2}$ ionized magnesium. In the case of a multiconfiguration model, single photoionization refers to the main expected state production.

Shake processes are due to a change of an effective potential of approximately one unit felt by outer shell electrons upon inner-shell ionization. As a result, one or more outer subshell electrons can be shaken, i.e. either shaken up to upper subshells or shaken off to continuum states (Åberg 1967). Both shake processes (noted hereafter as SU and SO) are important and their relative importance depends on outer subshell occupancy and symmetry. Typical relative probabilities for outermost subshell electrons to be shaken up or off upon inner shell ionization are approximately 10 to $20 \%$ (Carlson \& Nestor 1973). double shake (dS) processes, i.e. the processes where two outer electrons are excited or ionized, occur with much smaller probability (by about one order of magnitude less).

An understanding of the shake processes upon $2 \mathrm{~s}$ and $2 \mathrm{p}$ photoionization of magnesium can be obtained through the Sudden Perturbation Theory. In SPT, 
the outer-subshell 3s electrons are considered to be moving in the field created by the nucleus and all other electrons. After innershell ionization, the $3 \mathrm{~s}^{-}$-electron then finds itself in a new Hamiltonian, and it now has a non-zero probability to be found in any of the excited/ionized ns or $\epsilon \mathrm{S}$ states of the new Hamiltonian. SO and SU transitions are governed by monopole selection rules, and their probabilities can be calculated using the overlap integrals between the orbitals of the initial state and those of the innershell-ionized one (Sachenko \& Demekhin 1965). For magnesium the SU transitions will be mainly $3 \mathrm{~s} \rightarrow \mathrm{ns}$, while the $2 \mathrm{p} \rightarrow 3 \mathrm{p}$ excitation is very weak for an initial $2 \mathrm{~s}$ vacancy. There exists substantial experimental evidence that the SPT approximation gives good estimates for shake-off and shake-up probabilities as the result of photoionization as long as the photoelectron and shaken electron do not come from the same shell (Åberg 1969).

In contrast to the monopole shake processes discussed above, the conjugate shake-up excitation, $3 \mathrm{~s} \rightarrow 3 \mathrm{p}$ in our case, does not obey monopole selection rules, and it has to be treated in a more elaborate model, taking into account contributions due to collisions of the 2 s ejected electron with the outer subshell electrons. While monopole excitation probabilities reach constant relative energy value, the relative conjugate SU cross-section decreases rapidly with incident energy. However, for a large photon energy range, say up to two times the 2 s threshold energy, and for transitions with no change of principal quantum number, the conjugate shake--up is not a negligible feature (Badnell et al. 1997).

We employ a one-configuration approximation to calculate $2 \mathrm{~s}$ and $2 \mathrm{p}$ ionization cross-sections. Shake-up, shake-off and double shake probabilities are calculated using SPT. The R-matrix technique is employed to calculate shake-up and conjugate shake-up probabilities upon $2 \mathrm{~s}$ photoionization and to obtain the $\mathrm{L}_{1} \mathrm{~L}_{23} \mathrm{M}_{1}$ Coster-Kronig decay rates.

\section{L-shell photoionization and shake processes}

Calculated $2 \mathrm{p}$ and $2 \mathrm{~s}$ subshell cross sections are shown in Fig. 1. They are calculated in the one-configuration relaxed-core approximation using Dirac-Fock wavefunctions for both core electrons and the photoelectron (Kau et al. 1997). The energy scale is given in units $X=$ $h \nu / \mathrm{IP}_{2 \mathrm{~s}}$, defined as the ratio of the incident electron energy to the 2 s theoretical ionization potential.

Relative probabilities (defined with respect to single ionization) calculated with SPT for $\mathrm{Mg}$ and its isoelectronic series are listed in Table 1 . One can see that the probabilities of the shake processes upon $2 \mathrm{p}$ and $2 \mathrm{~s}$ ionization do not differ much. That is because the change of potential felt by a 3 s electron is approximately the same upon creation of either of the vacancies. Along the isoelectronic sequence, the relative change of potential weakens, and the shake probabilities decrease.

We use the R-matrix approach to describe both the $\mathrm{MgI}$ ground state and the diffusion $\mathrm{Mg}^{+}+\mathrm{e}^{-}$. The sets

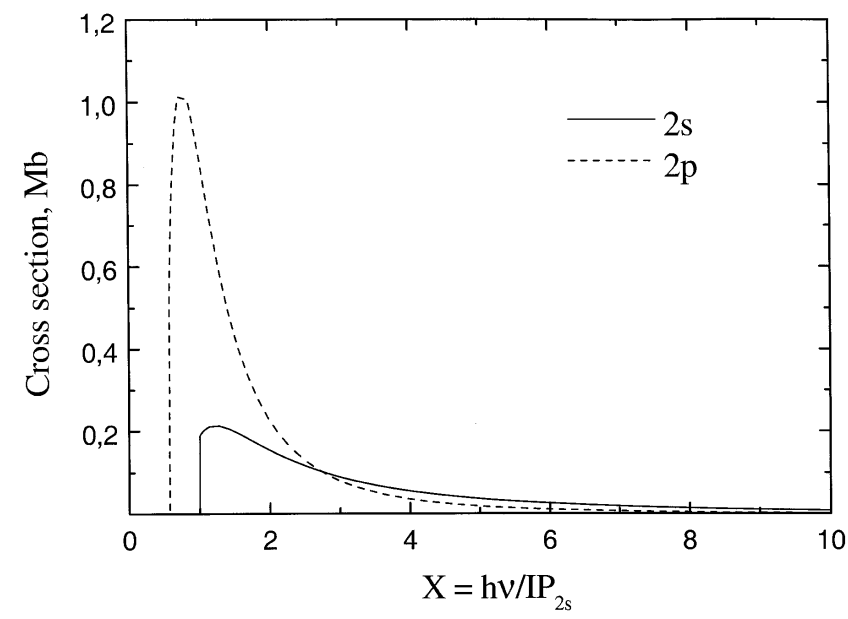

Fig. 1. L-photoionization cross section of atomic magnesium. $X$ is the ratio of photon energy to the 2 s subshell ionization potential

of terms were generated with the Superstructure code (Eissner et al. 1974). Each $n l$ orbital is defined by a scaling parameter $\lambda_{n l}$ obtained from an energy minimisation on a limited number of MgII low-lying terms. For the successive subshells, i.e. $1 \mathrm{~s}, 2 \mathrm{~s}, 2 \mathrm{p}, 3 \mathrm{~s}, 3 \mathrm{p}, 4 \mathrm{~s}$ and $4 \mathrm{p}$, these are: $1.4766,1.0488,0.9978,0.9241,0.9210$, $0.9174,0.9161$. Target configurations used are: i) the lower terms $1 \mathrm{~s}^{2} 2 \mathrm{~s}^{2} 2 \mathrm{p}^{6} 3 \mathrm{~s}, 3 \mathrm{p}, 4 \mathrm{~s}$, and $4 \mathrm{p}$; and the upper ones ii) $1 \mathrm{~s}^{2} 2 \mathrm{~s}^{2} 2 \mathrm{p}^{5} 3 \mathrm{~s}^{2}, 3 \mathrm{~s} 4 \mathrm{~s}$, and iii) $1 \mathrm{~s}^{2} 2 \mathrm{~s} 2 \mathrm{p}^{6} 3 \mathrm{~s}^{2}, 3 \mathrm{p}^{2}, 3 \mathrm{~s} 4 \mathrm{~s}$, and $3 \mathrm{~s} 3 \mathrm{p}$. The close-coupling expansions are completed by the bound channels: $1 \mathrm{~s}^{2} 2 \mathrm{~s}^{2} 2 \mathrm{p}^{6} 3 \mathrm{~s}^{2}, 3 \mathrm{p}^{2}$, and $3 \mathrm{~s} 4 \mathrm{~s}$. This method takes into account configuration interaction effects both in the target and the residual ion, as well as the channel coupling for the $\mathrm{Mg}^{+}+\mathrm{e}^{-}$free systems representing all possible scattering features.

Including all configurations i), ii) and iii) mentioned above in the close-coupling expansion, we obtain an ionization potential of $0.5558 \mathrm{Ry}$, a value which compares well with experimental result (Moore 1966). The 2s ionization potential is then $98.0 \mathrm{eV}$, which is slightly above the experimental value of $96.5 \mathrm{eV}$.

The relative $3 \mathrm{~s} \rightarrow 4 \mathrm{~s}$ SU probability obtained with the R-matrix approach reaches a constant value of $14 \%$ of the single ionization. The relative probability of the conjugate $3 \mathrm{~s} \rightarrow 3 \mathrm{p} \mathrm{SU}$ is $17.7 \%$ at $X=1.2$. It decreases with photon energy, but at $X=3$ is still about $4 \%$.

The SPT and R-matrix results for the $3 \mathrm{~s} \rightarrow 4 \mathrm{~s} \mathrm{SU}$ probability compare reasonably well (see Table 1 ). The SPT relative total shake probability following 2 s vacancy is $19.35 \%$. The $4 \mathrm{~s}$ and $5 \mathrm{~s}$ shake-up and shake-off relative probabilities are $17.03,0.9$ and $1.4 \%$ respectively. The shake-up probability dominates the shake-off. We feel that the contribution of the SO processes might be underestimated in SPT. The mean radii of the $1 \mathrm{~s}, 2 \mathrm{~s}, 2 \mathrm{p}$ and 3 s orbitals are $0.130,0.689,0.685$, and 3.249 au i.e. both $2 \mathrm{~s}$ and $1 \mathrm{~s}$ electrons are well inside the $3 \mathrm{~s}$ sphere. We then expect that the relative shake probabilities due 
Table 1. Relative probabilities (in \%) of shake processes upon L-shell ionization calculated within SPT

\begin{tabular}{ccccccc}
\hline Initial vacancy & Process & $\mathrm{Mg}$ & $\mathrm{Al}^{+}$ & $\mathrm{Si}^{++}$ & $\mathrm{P}^{+++}$ \\
\hline $2 \mathrm{~s}$ & $3 \mathrm{~s} \rightarrow 4 \mathrm{~s}$ & 17.03 & $14.05^{1}$ & 7.27 & 4.12 & 2.69 \\
$2 \mathrm{p}$ & & 18.07 & 7.93 & 4.59 & 3.05 \\
$2 \mathrm{~s}$ & $3 \mathrm{~s} \rightarrow 5 \mathrm{~s}$ & 0.89 & & 0.60 & 0.40 & 0.29 \\
$2 \mathrm{p}$ & & 0.96 & & 0.66 & 0.45 & 0.33 \\
$2 \mathrm{~s}$ & \multirow{2}{*}{$\mathrm{SO}$} & 1.43 & 0.91 & 0.61 & 0.43 \\
$2 \mathrm{p}$ & & 1.65 & & 1.15 & 0.79 & 0.59 \\
$2 \mathrm{~s}$ & $\mathrm{dS}$ & 0.93 & & 0.19 & 0.07 & 0.03 \\
$2 \mathrm{p}$ & & 1.07 & & 0.24 & 0.09 & 0.04 \\
\hline
\end{tabular}

\footnotetext{
${ }^{1} \mathrm{R}-$ matrix result.
}

Table 2. Relative probabilities of shake processes upon K-ionization of $\mathrm{Mg}$ (in \%)

\begin{tabular}{cccccc}
\hline & $3 \mathrm{~s} \rightarrow 4 \mathrm{~s}$ & $3 \mathrm{~s} \rightarrow 5 \mathrm{~s}$ & $3 \mathrm{~s} \mathrm{SO}$ & $2 \mathrm{p} \mathrm{SO}$ & Width, eV \\
\hline $\mathrm{SPT}$ & 21.3 & 1.1 & 2.4 & 4.3 & $0.304^{1}$ \\
Experiment $^{2}$ & 17.1 & 3.0 & 10.2 & 14.8 & 0.35 \\
\hline${ }^{1}$ Our calculation in one-configuration approximation. \\
${ }^{2}$ Breuckmann (1977).
\end{tabular}

Table 3. Auger and Coster-Kronig decay rates (in eV) for the MgII $1 \mathrm{~s}^{2} 2 \mathrm{~s}^{1} 2 \mathrm{p}^{6} 3 \mathrm{~s}^{2}$ state

\begin{tabular}{ccccccc}
\hline Approximation & \multicolumn{5}{c}{ Final state } & Width \\
\cline { 2 - 5 } & $2 \mathrm{p}^{6}$ & $2 \mathrm{p}^{5} 3 \mathrm{~s}\left({ }^{3} \mathrm{P}^{\circ}\right)$ & $2 \mathrm{p}^{5} 3 \mathrm{~s}\left({ }^{1} \mathrm{P}^{\circ}\right)$ & $2 \mathrm{p}^{5} 3 \mathrm{p}$ & $2 \mathrm{p}^{5} 4 \mathrm{~s}$ & \\
\hline R-matrix & 0.004 & 0.049 & 0.55 & 0.08 & 0.01 & 0.68 \\
One-configuration & 0.009 & 0.0005 & 0.7463 & & $0.010^{1}$ & 0.77 \\
\hline${ }^{1}$ Calculated with SPT as a result of the change of potential due to $\mathrm{L}_{1} \mathrm{~L}_{23} \mathrm{M}$ \\
Coster-Kronig decay.
\end{tabular}

to $1 \mathrm{~s}-$ vacancy must be close to those produced by $2 \mathrm{~s} / 2 \mathrm{p}-$ vacancies. Since the experimental data exist on shake probabilities upon 1s ionization (Breuckmann 1977, ionization by $3.8 \mathrm{keV}$ electron impact), we performed the SPT calculation on shake probabilities upon $\mathrm{K}$-ionization. Calculated shake probabilities are compared to the experimental data in Table 2. As one can see from Table 2, the SPT 3s SU probabilities compare well with the experiment $(21.3 \%+1.1 \%$ vs. $17.1 \%+3.0 \%)$. At the same time, the SO probabilities are underestimated, as expected. The SU processes dominate both theoretically and experimentally. We then consider the SPT SO data in Table 1 (about $1.5 \%$ ) to be a lower limit estimate of the SO probabilities upon L-ionization.

Although the main producer of the line-emitting excited states, MgIII $1 s^{2} 2 s^{2} 2 p^{5} 3 s$ is the decay of the $2 s^{-}$ vacancy (we shall address this aspect shortly), even below the $2 \mathrm{~s}-$ threshold these states can be produced via SO processes upon $2 \mathrm{p}$-ionization. This mechanism can give a noticeable contribution since in the L-threshold region the $2 \mathrm{p}$-ionization cross section is about five times greater than that of the $2 \mathrm{~s}-$-subshell (see Fig. 1).

\section{Decay of the MgII $1 s^{2} 2 s^{1} 2 p^{6} 3 s^{2}$ state}

Using the R-matrix and Superstructure codes, we analyse the resonant behaviour of the $\mathrm{S}$ scattering matrix of the $\mathrm{Mg}^{++}+\mathrm{e}^{+}$collision for large incident energies, i.e. in the vicinity of the $2 \mathrm{~s} 2 \mathrm{p}^{6} 3 \mathrm{~s}^{2}$ term (Brenig \& Haag 1959). The scaling parameters used for $1 \mathrm{~s}, 2 \mathrm{~s}, 2 \mathrm{p}, 3 \mathrm{~s}, 3 \mathrm{p}, 4 \mathrm{~s}$ are $1.4700,1.0489,0.9996,1.0251,1.01621,1.02992$ respectively with all terms issued from configurations $2 \mathrm{p}^{6}, 2 \mathrm{p}^{5} 3 \mathrm{~s}$, $3 \mathrm{p}, 4 \mathrm{~s}$. Two closed channels from configuration $2 \mathrm{~s} 2 \mathrm{p}^{6} 3 \mathrm{~s}$ are present. The bound channels are $2 \mathrm{~s} 2 \mathrm{p}^{6} 3 \mathrm{~s}^{2}, 3 \mathrm{~s} 4 \mathrm{~s}, 3 \mathrm{p}^{2}$. The total calculated Auger width is $0.68 \mathrm{eV}$.

The decay probabilities obtained within the R-matrix technique are presented in Table 3 together with those obtained in a one-electron approximation using Hartree-Fock wavefunctions for both core and Auger/Coster-Kronig electrons. This comparison demonstrates strong CI and channel coupling effect on branching ratios. Thus in the one-electron approximation, the $2 \mathrm{p}^{5} 3 \mathrm{~s}\left({ }^{1} \mathrm{P}^{\mathrm{o}}\right)$ final state has 
a branching ratio of about $99 \%$ while upon allowance of CI and channel coupling it is $80.3 \%$. Note that shakeoff in the Auger decay itself occurs simultaneously, i.e. ionization of a second electron.

It follows from the results presented in Table 3 that single ionization of the $2 \mathrm{~s}$ subshell will result predominantly in emission of the line issued from the $2 \mathrm{p}^{5} 3 \mathrm{~s}\left({ }^{1} \mathrm{P}^{\mathrm{o}}\right)$ state. At the same time as the SU states such as $1 \mathrm{~s}^{2} 2 \mathrm{~s} 2 \mathrm{p}^{6} 3 \mathrm{~s} 4 \mathrm{~s}$ are produced with noticable probability, these will give rise to another emission state MgIII $2 \mathrm{p}^{5} 4 \mathrm{~s}$.

\section{Conclusion}

The example of magnesium confirms that L-shake processes are important comprising $20-30 \%$ of the single ionization process, the conjugate excitation is substantial over a large energy interval. The $\mathrm{Mg}^{++} 2 \mathrm{p}$-hole state ${ }^{1} \mathrm{P}^{\mathrm{o}}$ production following $2 \mathrm{~s}$ vacancy is favoured. This is a general feature of the $2 \mathrm{~s}$-hole decay for the third-row atoms and ions. In others words radiationless decay creates mostly $2 \mathrm{p}$-hole excited states of the residual ion. These $2 \mathrm{p}$-hole states will Auger decay. Let us now consider the ground state of atomic Phosphorus $1 \mathrm{~s}^{2} 2 \mathrm{~s}^{2} 2 \mathrm{p}^{6} 3 \mathrm{~s}^{2} 3 \mathrm{p}^{3}{ }^{4} \mathrm{~S}^{\mathrm{o}}$. Upon $2 \mathrm{~s}-$ ionization, we see creation of $2 \mathrm{~s} 2 \mathrm{p}^{6} 3 \mathrm{~s}^{2} 3 \mathrm{p}^{3}{ }^{3} \mathrm{~S}^{\circ}$ and ${ }^{5} \mathrm{~S}^{\circ}$. $2 \mathrm{~s} 2 \mathrm{p}^{6} 3 \mathrm{~s}^{2} 3 \mathrm{p}^{3} \rightarrow 2 \mathrm{~s}^{2} 2 \mathrm{p}^{6} 3 \mathrm{~s}^{2} 3 \mathrm{p}, 2 \mathrm{~s}^{2} 2 \mathrm{p}^{6} 3 \mathrm{~s} 3 \mathrm{p}^{2}, 2 \mathrm{~s}^{2} 2 \mathrm{p}^{6} 3 \mathrm{p}^{3}$ (Auger)

$$
\text { or } \rightarrow 2 \mathrm{~s}^{2} 2 \mathrm{p}^{5} 3 \mathrm{~s}^{2} 3 \mathrm{p}^{2}, 2 \mathrm{~s}^{2} 2 \mathrm{p}^{5} 3 \mathrm{~s} 3 \mathrm{p}^{3} \text { (Coster-Kronig) }
$$

and again by Auger cascade

$$
\rightarrow 2 \mathrm{~s}^{2} 2 \mathrm{p}^{6} 3 \mathrm{~s}^{2}, 2 \mathrm{~s}^{2} 2 \mathrm{p}^{6} 3 \mathrm{~s} 3 \mathrm{p}, 2 \mathrm{~s}^{2} 2 \mathrm{p}^{6} 3 \mathrm{p}^{2} \text {. }
$$

Similarly, the shake-off terms are $2 \mathrm{~s} 2 \mathrm{p}^{6} 3 \mathrm{~s}^{2} 3 \mathrm{p}^{2}{ }^{2} \mathrm{P}$ and ${ }^{4} \mathrm{P}$ and we have:

$$
\begin{aligned}
& 2 \mathrm{~s} 2 \mathrm{p}^{6} 3 \mathrm{~s}^{2} 3 \mathrm{p}^{2} \rightarrow 2 \mathrm{~s}^{2} 2 \mathrm{p}^{6} 3 \mathrm{~s}^{2}, 2 \mathrm{~s}^{2} 2 \mathrm{p}^{6} 3 \mathrm{~s} 3 \mathrm{p}, 2 \mathrm{~s}^{2} 2 \mathrm{p}^{6} 3 \mathrm{p}^{2} \\
& \text { or } \rightarrow 2 \mathrm{~s}^{2} 2 \mathrm{p}^{5} 3 \mathrm{~s}^{2} 3 \mathrm{p},{ }^{2} 2 \mathrm{p}^{5} 3 \mathrm{~s} 3 \mathrm{p}^{2}
\end{aligned}
$$

and finally $\rightarrow 2 \mathrm{~s}^{2} 2 \mathrm{p}^{6} 3 \mathrm{~s}, 2 \mathrm{~s}^{2} 2 \mathrm{p}^{6} 3 \mathrm{p}$.

Note that if we add the probabilities of Auger-Shake off, the degree of ionization of the residual ion reaches six. Each stage of ionization gives rise to groups of lines which are well defined. Obviously, theoretical difficulties arise due to the breakdown of LS coupling in $2 \mathrm{p}$-hole configurations. The $2 \mathrm{~s}-$ hole atomic magnesium leads to the emission of a unique relatively strong line and to the production of a ground state of once, twice and multiply-ionized targets. Such scenarios are efficient in the haloes of PN where the hardening of the radiation field is due to the fact that the central region is almost optically thick to ionizing radiation, so that the more energetic photons preferentially reach the halo (Machando \& Pottasch 1989). For low electron density plasmas undergoing soft $\mathrm{X}$-irradiation (say above a few hundred $\mathrm{eV}$ ), relative intensities of these lines, issued from successive ionization states, are mainly determined by Auger and Coster-Kronig rates.

Acknowledgements. One of the authors (AGK) would like to thank his colleagues from Laboratoire Cassini UMR 6529 for their hospitality during his stay in Nice.

\section{References}

Åberg, T. 1969, Ann. Acad. Sci. Fennicae A, IV, 308

Badnell, N. R., Petrini, D., \& Stoica, S. 1997, J. Phys. B: At. Mol. Phys., 30, L665

Bambynek, W., Crasemann, B., Fink, R. W., et al. 1972, Rev. Mod. Phys., 44, 716

Berrington, K. A., Burke, P. G., \& Butler, K. 1987, J. Phys. B: At. Mol. Phys., 20, 6379

Brenig, W., \& Haag, R. 1959, Fortschr. Phys., 7, 183

Breuckmann, B. 1977, Thesis, Universitat zu Freiburg i. Br., 121

Carlson, T. A. \& Krause, M. O. 1965, Phys. Rev., 137, A1655

Carlson, T. A., \& Nestor, C. W. Jr. 1973, Phys. Rev. A, 8, 2887

Eissner, W., Jones, M., \& Nussbaumer, H. 1974, Comput. Phys. Commun., 8, 270

Kau, R., Petrov, I. D., Sukhorukov, V. L., \& Hotop, H. Z. 1997, Phys. D., 39, 267

Krause, M. O. 1971, J. Phys. (France) Colloq., 32, C4-67

Kochur, A. G., Sukhorukov, C. L., Petrov, I. D., \& Demekhin, Ph. V. 1995, J. Phys. B. At. Mol. Opt. Phys., 28, 387

Manchando, A., \& Pottasch, S. R. 1989, A\&A, 222, 219

Moore, C. E. 1966, Atomic Energy Levels, NBS Circular No. 467, vol. 1, US Government Printing Office, Washington DC

Sachenko, V. P., \& Demekhin, V. F. 1965, J. Exper. Theor. Phys. (USSR), 49, 765 